\title{
A three-stage continuous culture approach to study the impact of probiotics, prebiotics and fat intake on faecal microbiota relevant to an over 60s population
}

Article

Accepted Version

Creative Commons: Attribution-Noncommercial-No Derivative Works 4.0

Liu, Y., Gibson, G. R. and Walton, G. E. (2017) A three-stage continuous culture approach to study the impact of probiotics, prebiotics and fat intake on faecal microbiota relevant to an over 60s population. Journal of Functional Foods, 32. pp. 238247. ISSN 1756-4646 doi:

https://doi.org/10.1016/j.jff.2017.02.035 Available at https://centaur.reading.ac.uk/75076/

It is advisable to refer to the publisher's version if you intend to cite from the work. See Guidance on citing.

To link to this article DOI: http://dx.doi.org/10.1016/j.jff.2017.02.035

Publisher: Elsevier

All outputs in CentAUR are protected by Intellectual Property Rights law, including copyright law. Copyright and IPR is retained by the creators or other copyright holders. Terms and conditions for use of this material are defined in the End User Agreement. 


\section{www.reading.ac.uk/centaur}

\section{CentAUR}

Central Archive at the University of Reading

Reading's research outputs online 
8

9

0
Yue Liu, Glenn R Gibson, Gemma E Walton \#

Department of Food and Nutritional Sciences

Whiteknights, PO Box 226

University of Reading,

Reading

United Kingdom

Running title: Aging, prebiotics, probiotics, microbiota and immunity

\# Address correspondence to Gemma E Walton, g.e.walton@ reading.ac.uk

Glenn R Gibson, Yue Liu, Gemma E Walton designed the study.

Yue Liu conducted acquisition, analysis and interpretation of data.

Yue Liu drafted the manuscript, Glenn R Gibson, Gemma E Walton conducted critical revision. 


\section{Abstract}

25 This study aimed to determine the impact of fat intake combined with Bacillus coagulans or trans-galactooligosaccharides (B-GOS) on bacterial composition and immune markers in an in vitro model. A three-stage continuous gut model system was used to simulate specific human colonic regions. Peripheral blood mononuclear cells were exposed to cell free supernatants and subsequent levels of inflammatory cytokines were measured by flow cytometry. Although fat addition decreased bifidobacteria from $8.76 \pm 0.12$ to $8.63 \pm 0.13$ and from $8.83 \pm 0.08$ to $8.67 \pm 0.07$ in pre- and probiotic models respectively, the changes were not significant. Fat addition also did not impact on cytokines induced by LPS. Under high fat conditions, numbers of bifidobacteria significantly increased by B. coagulans or B-GOS. In addition, B. coagulans or B-GOS significantly suppressed TNF-aproduction induced by LPS. Under high fat conditions, either B. coagulans or B-GOS led to potentially beneficial effects by targeting specific bacterial groups and modulating immune markers.

\section{Abbreviations}

B-GOS, trans-galactooligosaccharides; IL-6, interleukin-6; IL-1 $\beta$, interleukin-1 $\beta$; TNF- $\alpha$, tumour necrosis factor- $\alpha$; NK, natural killer; FISH, fluorescent in situ hybridisation; SS, steady state; SCFA, short-chain fatty acid; GC, gas chromatography; PBMCs, peripheral blood mononuclear cells; LPS, lipopolysaccharide

\section{Keywords}

43 Probiotics; Prebiotics; Fat; Microbiota; Immune markers 
Galactooligosaccharides (PubChem CID: 165512).

\section{Introduction}

It has been reported that between the years 2000 and 2050, the percentage of the population aged 60 and over is likely to double from about $11 \%$ to $22 \%$ (WHO, 2014). Subsequently, requirements for long-term care, including home nursing, are increasing. Compared to young adults, elderly people suffer from some physical and functional changes. For example, poor chewing and swallowing (Castell, 1988; Karlsson, Persson, \& Carlsson, 1991; Remond et al., 2015) can result in reduced dietary choice, poor nutrition, digestion and absorption (Remond et al., 2015). In terms of effects on the gastrointestinal tract, Woodmansey, McMurdo, Macfarlane, and Macfarlane (2004) suggested that less gastrointestinal mobility and longer transit time might result in a higher susceptibility to colon disorders.

In addition, elderly populations typically have increased levels of cytokines associated with inflammation such as interleukin-6 (IL-6), IL-1 $\beta$, and tumour necrosis factor- $\alpha$ (TNF- $\alpha$ ), along with decreased phagocytosis and natural killer (NK) cell activity. These immunological changes are loosely termed immunosenescence (Bruunsgaard, Pedersen, Schroll, Skinhoj, \& Pedersen, 2001; Butcher et al., 2001; Goodwin, 1995; Schiffrin, Morley, Donnet-Hughes, \& Guigoz, 2010; Vulevic, Drakoularakou, Yaqoob, Tzortzis, \& Gibson, 2008).

The combination of age-related changes in the gastrointestinal tract, such as decreased transit

64 time and increased mucosal membrane permeability (Hopkins, Sharp, \& Macfarlane, 2002), dietary changes on the microbiota (Candela, Biagi, Turroni, Rampelli, \& Brigidi, 2015; Rampelli et al., 2013a; Rampelli et al., 2016; Vulevic et al., 2008). Indeed, studies have shown

67 decreased viable counts of Bacteroides in elderly compared to younger adults (Hopkins \& Macfarlane, 2002; Woodmansey et al., 2004). A reduction of bifidobacteria in numbers and 
species diversity is one of the most notable changes in elderly populations and has been reported in studies using traditional culture methods as well as molecular methods (Claesson et al., 2011; Gavini et al., 2001; Hopkins \& Macfarlane, 2002; Hopkins, Sharp, \& Macfarlane, 2001; Mitsuoka, 1992; Mueller et al., 2006; Woodmansey et al., 2004). In addition, the agerelated microbiota changes in elderly were associated with decreased short-chain fatty acid (SCFA) production, 90-95\% of which are acetate, propionate, and butyrate and originate from fermentation of non-digestible carbohydrates (Puddu, Sanguineti, Montecucco, \& Viviani, 2014). Elderly individuals were characterised with decreased saccharolytic fermentation and increased proteolytic fermentation compared to younger adults (Rampelli et al., 2013c). These age-related changes in microbiota composition may drive some of the immune response changes and could lead to higher disease risk in elderly compared to younger adults. According to a recent report (Bates, Lennox, Prentice, Bates, \& Swan, 2012), a typical elderly person's daily intake of total fat is $36.1 \%$ food energy of which $14.2 \%$ is saturated fatty acids, these are higher than the UK Dietary Reference Values, of 35\% and 11\% respectively. In murine studies, a high fat diet has been shown to have negative effects on microbiota composition, including, for example lower Bacteroides group and higher Firmicutes phylum in animal models (Cani et al., 2007a; Cani et al., 2007i; Pyndt Jørgensen et al., 2014; Rampelli et al., 2016). A high fat diet may also impact upon Clostridium spp. and Lactobacillus spp., which have been observed to decrease following high fat treatments (Biagi et al., 2010; Cani et al., 2007a; Druart et al., 2013). High fat diets are also associated with a negative impact on immune function in murine studies. For example, increased levels of TNF- $\alpha$, IL-1 $\beta$ and IL-6 in plasma and tissues following a high fat diet have been observed in animal models, subsequently resulting in greater inflammatory status (Cani et al., 2007a; Cani et al., 2007i; Chen, Wang, Li, \& Wang, 2011; Kim, Gu, Lee, Joh, \& Kim, 2012; Lam et al., 2012; Neyrinck et al., 2011; Park et al., 2013). Because elderly people are consuming high fat diets, they may additionally be 
more vulnerable to disease risk. Therefore, the impact of high fat consumption on elderly persons may be relevant.

Several murine studies have shown that prebiotics and probiotics can positively modulate the gut microbial composition and immune markers following a high fat diet (Cani et al., 2007i;

Chen et al., 2011; Park et al., 2013). Trans-galactooligosaccharides (B-GOS) are promising prebiotics that have been observed to positively improve microbiota composition and immune function in the elderly (Vulevic et al., 2008; Vulevic et al., 2015). The impact of B-GOS following a high fat diet has not been investigated. However, B-GOS was shown to increase the number of faecal bifidobacteria and decrease $C$. histolyticum group in overweight adults

103 (Vulevic, Juric, Tzortzis, \& Gibson, 2013). B-GOS may have promising potential to modulate 104 microbiota composition and immune markers in elderly under high fat intakes. Bacillus coagulans GBI-30, 6086 (GanedenBC $\left.{ }^{30}(\mathrm{BC} 30)\right)$ has the potential to suppress the growth of pathogens (Honda, Gibson, Farmer, Keller, \& McCartney, 2011). B. coagulans can also modulate the microbiota with significant increases observed in Bacillus spp., C. litsueburense and $F$. prausnitzii after 28 -day supplementation in healthy elderly adults (65 and 80 years)

109 (Nyangale, Farmer, Keller, Chernoff, \& Gibson, 2014). In an in vitro study, both the cell wall and metabolite fractions of $B$. coagulans induced IL-10 production, thereby demonstrating anti-

111 inflammatory potential. This suggests immune modulating effects of BC30 B. coagulans

112 (Jensen, Benson, Carter, \& Endres, 2010) which could help to combat both ageing and high-

113 fat diet effects. In addition, the safety of Bacillus coagulans GBI-30, 6086 has been confirmed

114 including exerting no mutagenic, clastogenic or genotoxic effects (Endres et al., 2009), 115 harbouring no risk-associated genes and producing no biogenic amine (Salvetti et al., 2016).

116 Recent studies have provided a good indication about prebiotic and probiotic effects on elderly 117 populations. However, the influence of prebiotic and probiotic (B-GOS and B. coagulans) on 118 elderly persons in the presence of high fats has not been well studied. Therefore, the aim of the 
119 current study was to assess the impact of B. coagulans and B-GOS on bacterial composition 120 and immune markers in senior individuals consuming a high fat diet using a three-stage gut 121 model.

\section{2. Materials and methods}

\section{2.1. Chemicals and bacteria}

124 Unsalted butter (Sainsbury's basics, UK), sunflower oil (Sainsbury's SO Organic, UK) and olive oil (Filippo Berio, UK) were from Sainsbury's supermarket (Reading, UK). Coconut oil was from Holland and Barrett (Reading, UK). B-GOS mixture was from Clasado Ltd (Milton Keynes, UK), the degree of polymerisation ranged from 2 to 5, average molecular weight was $496.8 \mathrm{kDa}$, and galactooligosaccharide content of B-GOS mixture was $58 \%$ (w/w). Bacillus coagulans: GBI-30 (PTA-6086, GanedeBC ${ }^{30} \mathrm{TM}$ ) was sourced from American Type Culture

130 Collection (Manassas, United States) and was used as spores in the current study. All nucleotide probes used for fluorescent in situ hybridisation (FISH) were commercially synthesised and labelled with the fluorescent dye Cy3 at the 5' end (Sigma Aldrich Co. Ltd., Spain). Sterilisation of media and instruments was done by autoclaving at $121^{\circ} \mathrm{C}$ for $15 \mathrm{~min}$.

\subsection{Three-stage continuous culture system}

The physicochemical conditions in the colon were replicated in the three-stage continuous system, as validated by Macfarlane, Macfarlane, and Gibson (1998). It was set up simulating, the proximal, transverse and distal colon, which were present as three connected fermentation vessels (V1, V2, and V3). Faecal samples were donated by three healthy persons aged over 60 years old ( 2 female and 1 male). Volunteers were not regular consumers of pre or probiotics and had not received antibiotic treatment in the previous three months. A different faecal donor

141 was used for each of the three repetitions. A $20 \%(\mathrm{w} / \mathrm{v})$ faecal slurry $(28.57 \mathrm{ml}(\mathrm{V} 1), 33.33 \mathrm{ml}$ 142 (V2), $37.5 \mathrm{ml}(\mathrm{V} 3)$ ) was inoculated into culture medium (51.43 $\mathrm{ml}(\mathrm{V} 1), 66.67 \mathrm{ml}$ (V2), 82.5 
$143 \mathrm{ml}$ (V3)) and left to equilibrate for 24 hours as a batch culture system. Briefly, culture medium 144 was prepared in distilled water and consisted of $\left(\right.$ litre $\left.^{-1}\right): 5 \mathrm{~g}$ starch, $5 \mathrm{~g}$ peptone water, $5 \mathrm{~g}$ 145 tryptone, $4.5 \mathrm{~g}$ yeast extract, $4.5 \mathrm{~g} \mathrm{NaCl}, 4.5 \mathrm{~g} \mathrm{KCl}, 4 \mathrm{~g}$ mucin (porcine gastric type III), $3 \mathrm{~g}$ casein, $1462 \mathrm{~g}$ pectin (citrus), $2 \mathrm{~g}$ xylan (oatspelt), $2 \mathrm{~g}$ arabinogalactan (larch wood), $1.5 \mathrm{~g} \mathrm{NaHCO}, 1.25 \mathrm{~g}$

$147 \mathrm{MgSO}_{4} .7 \mathrm{H}_{2} \mathrm{O}, 1 \mathrm{~g}$ guar gum, $1 \mathrm{~g}$ inulin, $0.8 \mathrm{~g}$ cysteine, $0.5 \mathrm{~g} \mathrm{KH}_{2} \mathrm{PO}_{4}, 0.5 \mathrm{~g} \mathrm{~K} \mathrm{HPO}_{4}, 0.4 \mathrm{~g}$ bile 148 salts No. 3, 0.15g CaCl $2.6 \mathrm{H}_{2} \mathrm{O}, 0.005 \mathrm{~g} \mathrm{FeSO} 4.7 \mathrm{H}_{2} \mathrm{O}, 0.05 \mathrm{~g}$ hemin, $10 \mu \mathrm{l}$ Vitamin $\mathrm{K}$ and $1 \mathrm{ml}$ 149 Tween 80. Following this, the medium flow was turned on with a system retention time of 48 150 hours, culture temperature was $37^{\circ} \mathrm{C}$ and $\mathrm{pH}$ in each vessel was 5.5 (V1), 6.2 (V2), 6.8 (V3), 151 these were maintained using a pH pump (Electrolab, UK) with $0.5 \mathrm{M} \mathrm{NaOH}$ and $\mathrm{HCl}$ solutions 152 as appropriate. An anaerobic environment was maintained by continuous sparging of oxygen153 free nitrogen supply $(15 \mathrm{~mL} / \mathrm{min})$.

154 During in vitro fermentation, the initial steady state (SS1), when equilibrium was reached, was at day 16. This was confirmed by stabilisation of SCFA profiles after three consecutive days. 156 Following SS1, high fat mixture (4.78g), (unsalted butter $2 \mathrm{~g}$, coconut oil $0.83 \mathrm{~g}$, sunflower oil $157 \quad 1.17 \mathrm{~g}$ and olive oil 1.33g) was added into vessel 1 daily (Table 1). A second steady state (SS2) 158 was reached after 35 days. SS3 involved daily addition of the same amount of fat mixture as 159 SS2 and either probiotic (B. coagulans) or prebiotic B-GOS mixture treatment until equilibrium 160 at 53 days. B. coagulans (GanedenBC30) was added into V1 at a dose of $3.3 \times 10^{8}$ cfu daily 161 (Table 1). Another 3 gut systems were fed 2.5g of B-GOS mixture in V1 daily. This B-GOS 162 mixture consisted of the following ingredients: glucose $0.394 \mathrm{~g}$; galactose $0.017 \mathrm{~g}$; lactose $1630.348 \mathrm{~g}$; B-GOS $1.063 \mathrm{~g}$; protein $0.003 \mathrm{~g}$; ash $0.008 \mathrm{~g}$ and moisture $0.611 \mathrm{~g}$, in which the B-GOS content of B-GOS mixture was $58 \%(\mathrm{w} / \mathrm{w})$. The same amounts of glucose, galactose and lactose were also added to non-prebiotic fed gut models daily (Table 1). Samples (5ml) were collected from each vessel at each steady state over three consecutive days for further analysis. 


\subsection{Sample preparation}

168 A sample of $375 \mu 1$ (in duplicate) was taken for FISH analysis. This sample was fixed 169 immediately in $4 \%(\mathrm{w} / \mathrm{v})$ paraformaldehyde solution $(1125 \mu \mathrm{l})$ at $4^{\circ} \mathrm{C}$ for 4 hours, then 170 centrifuged for 5 minutes at $11337 \mathrm{~g}$ (Eppendorf centrifuge minispin, Eppendorf, UK) at room 171 temperature. The supernatant was carefully removed and discarded. The pellet was re172 suspended in $1 \mathrm{ml}$ of cold $1 \times \mathrm{PBS}$ by aspirating carefully using a pipette. Again, the sample was centrifuged for 5 minutes at $11337 \mathrm{~g}$ at room temperature and the supernatant discarded.

174 The sample was washed again in $1 \mathrm{ml}$ cold PBS as above and centrifuged. All supernatant was carefully removed. Finally, the pellet was re-suspended in $150 \mu 1$ cold $1 \times \mathrm{PBS}$ and $150 \mu 1$

176 ethanol. The sample was mixed by vortexing and then stored at $-20^{\circ} \mathrm{C}$, for FISH based analysis 177 of bacterial counts.

178 In preparation for SCFA analysis, $1 \mathrm{ml}$ duplicate samples were taken and centrifuged (11337 $\mathrm{g}$, $10 \mathrm{~min}$ ) at room temperature. The supernatant was stored at $-20^{\circ} \mathrm{C}$ for future analysis. In preparation for in vitro immunoassays, $1 \mathrm{ml}$ of gut model supernatant was sampled in

181 triplicate, centrifuged for 10 minutes at $11337 \mathrm{~g}$ at room temperature and then filtered through 182 a $0.22 \mu \mathrm{m}$ filter device (Millipore, Schwalbach, Germany). The cell-free supernatant was stored 183 at $-20^{\circ} \mathrm{C}$.

\subsection{Bacterial enumeration}

185 FISH analysis involved the use of fluorescently labelled oligonucleotide probes (using Cy3), targeting specific 16S rRNA sequences (Daims, Stoecker, \& Wagner, 2005). The probes used in this study were: Ato 291 for Atopobium cluster (Atopobium, Coriobacterium, Collinsella spp.) (Harmsen et al., 2000), Lab 158 for lactobacilli/enterococci (Harmsen, Elfferich, Schut,

$189 \&$ Welling, 1999), Bif 164 for bifidobacteria (Langendijk et al., 1995), Erec 482 for

190 Eubacterium rectale - Clostridium coccoides group (Franks et al., 1998), Chis 150 for the 191 Clostridium histolyticum group (Franks et al., 1998), Bcoa 191 for Bacillus spp. (Sakai \& Ezaki, 
192 2006), Bac 303 for Bacteroides-Prevotella spp. (Manz, Amann, Ludwig, Vancanneyt, \&

193 Schleifer, 1996), and EUB 338 mixture consisting of EUB338, EUB338II and EUB338III for

194 total bacteria (Daims, Bruhl, Amann, Schleifer, \& Wagner, 1999). Conditions of hybridisation

195 and washing for individual probes are given in Supplementary 1. Hybridisation of samples was

196 performed as described by Daims et al. (2005).

197 Briefly, fixed samples were kept on ice and diluted with PBS solution, then $20 \mu$ diluted 198 suspension was evenly placed onto a 5mm diameter well in Teflon- and poly L-lysine-coated

199 slide (Tekdon Inc, Myakka City, FL). These slides were dried for $15 \min$ at $46-50^{\circ} \mathrm{C}$ and 200 washed in 50\%, 80\% and 96\% (v/v) ethanol solution for 3 minutes respectively, then dried for

$2012 \mathrm{~min}$. Some Gram-positive bacteria needed lysozyme treatment prior to hybridisation, such as

202 bifidobacteria and lactobacilli/enterococci. $20 \mu \mathrm{l}$ of lysozyme $(1 \mathrm{mg} / \mathrm{ml})$ was therefore added 203 to each well before dehydration in ethanol. Following this, $50 \mu$ l pre-warmed hybridisation buffer (0.9 M NaCl, 0.02 M Tris/HCl (pH 8.0), (Supplementary 1), $0.05 \mu 110 \%$ (w/v) sodium dodecyl sulphate, $39.95 \mu \mathrm{HPLC}$ water and $4.55 \mathrm{ng} \mathrm{ml}^{-1}$ probe) were added to each well, and slides placed on a tray, which was sealed and put in a hybridisation oven for $4 \mathrm{~h}$ at probe specific hybridisation temperature (Supplementary 1). $20 \mu 1$ nucleic acid stain 4', 6-diamidino-2phenylindole (DAPI; $50 \mathrm{ng} \mu \mathrm{l}-1$ ) was added to the wash buffer before hybridisation finished. Once the hybridisation was complete, slides were placed into wash buffer $(0.9 \mathrm{M} \mathrm{NaCl}, 0.02$ M Tris/HCl ( $\mathrm{pH} 8.0), 0.005 \mathrm{M}$ ethylenediaminetetraacetic acid (EDTA) solution ( $\mathrm{pH}$ 8.0,

211 Supplementary 1), $\mathrm{H}_{2} \mathrm{O}$ ), warmed at the appropriate temperature for each probe

212 (Supplementary 1) for 10-15 minutes. After washing, slides were dipped into ice-cold distilled water for 2-3 seconds and dried by a stream of compressed air. Finally, antifade solution (Dabco)

214 was added to each well, a cover slip applied and slides examined using fluorescence 215 microscopy (Nikon Eclipse E400; Nikon, Tokyo, Japan). 


\subsection{Organic analysis}

217 SCFAs were determined by gas chromatography (GC) following N-(tert-butyldimethylsilyl)-

218 N-methyltrifluoroacetamide derivitisation (Richardson, Calder, Stewart, \& Smith, 1989). Each

219 sample was vortexed and $1 \mathrm{ml}$ of sample or a standard solution transferred into a labelled 100

$220 \mathrm{~mm} \times 16 \mathrm{~mm}$ glass tube (Fisher Scientific UK Ltd, Loughborough) with $50 \mu 1$ of 2-ethylbutyric

221 acid ( $0.1 \mathrm{M}$ internal standard solution), $500 \mu \mathrm{l}$ concentrated $\mathrm{HCl}$ and $2 \mathrm{ml}$ diethyl ether. All

222 samples were vortexed for $1 \mathrm{~min}$ and centrifuged at $2000 \mathrm{~g}$ for $10 \mathrm{~min}$ at room temperature

223 (SANYO MSE Mistral 3000i, Sanyo Gallenkap PLC, UK) twice (1 ml of diethyl ether added

224 in second extraction), aiming to completely extract the SCFAs. $400 \mu 1$ of the pooled ether

225 extract and $50 \mu 1 \mathrm{~N}$-(tert-butyldimethylsilyl)-N-methyltrifluoroacetamide (MTBSTFA) were

226 added into a GC screw-cap vial. Samples were heated at $80^{\circ} \mathrm{C}$ for $20 \mathrm{~min}$ and kept at room

227 temperature for $48 \mathrm{~h}$ to enable further derivatisation.

228 A 5890 SERIES II Gas Chromatograph (Hewlett Packard, UK) using an Rtx-1 10m×0.18mm

229 column with a $0.20 \mu \mathrm{m}$ coating (Crossbond $100 \%$ dimethyl polysiloxane; Restek,

230 Buckinghamshire, UK) was used for SCFA analysis. Temperature of injector and detector was

$231275^{\circ} \mathrm{C}$, with the column programmed from $63^{\circ} \mathrm{C}$ for 3 minutes to $190^{\circ} \mathrm{C}$ at $10^{\circ} \mathrm{C} \mathrm{min}{ }^{-1}$ and held

232 at $190^{\circ} \mathrm{C}$ for 3 minutes. Helium was the carrier gas (flow rate $1.2 \mathrm{ml} \mathrm{min}^{-1}$; head pressure 90

$233 \mathrm{MPa}$ ). A split ratio of 100:1 was used. The SCFA external standard was run every 20 samples

234 to update the calibration as necessary. The SCFA external standard solution contained (mM):

235 sodium formate, 10; acetic acid, 30; propionic acid, 20; isobutyric acid, 5; n-butyric acid, 20;

236 iso-valeric acid, 5; n-valeric acid, 5; sodium lactate, 10; sodium succinate, 20. This standard

237 was treated the same as the samples and derivatised with added internal standard. Peak areas

238 of the standard solution, to which internal standard was added, were used to calculate the

239 response factors for each organic acid with respect to the internal standard. Response factor

240 and peak areas within samples were calibrated and calculated using Chemstation B.03.01 
241 (Agilent Technologies, Cheshire, UK). Response factors were calculated using Equation 1. The 242 amount of organic acids with the samples was calculated using Equation 2.

$$
\text { Internal Response Factor }=\frac{\text { areaIS } \times \text { amount } S C}{\text { amount } I S \times \text { areaSC }}
$$

Equation 1 IS=Internal Standard; SC=Specific Compound of Interest

$$
\text { Amount of Specific Compound }=\frac{\text { amountIS } \times \text { areaSC } \times I R F S C}{\text { areaIS }}
$$

Equation 2 IS=Internal Standard; SC=Specific Compound of Interest; IRFSC=Internal Response

Factor for Specific Compound of Interest

\subsection{Preparation of peripheral blood mononuclear cells}

250 Fasted blood samples were taken from six healthy volunteers aged $60-75$ years, in sodium

251 heparin vacutainer tubes (Greiner Bio-One Limited, Gloucestershire, UK). The study was

252 conducted according to guidelines laid down in the Declaration of Helsinki 1975, as revised in

253 1983. All procedures involving human subjects were approved by the Ethics Committee of the

254 University of Reading. Written informed consent forms was obtained from all subjects. Blood was layered over an equal volume of lympholyte (Cedarlane Laboratories Limited, Burlington, Ontario, Canada) and centrifuged at $930 \mathrm{~g}$ for $15 \mathrm{~min}$ at room temperature. Peripheral blood mononuclear cells (PBMCs) were harvested from the interface, washed once with PBS and then resuspended in Roswell Park Memorial Institute (RPMI) 1640 medium (containing glutamine, Roswell Park Memorial Institute, Autogen Bioclear Ltd., Wiltshire, UK). These steps were repeated to obtain low contamination levels of erythrocytes. The pellet was resuspended in RPMI 1640 medium and cell numbers counted using a cell counter (Coulter,

262 Fullerton, CA, USA) and trypan blue. 


\subsection{Viability assays}

264 To determine the appropriate supernatant concentration, PBMC viability, at different 265 supernatant concentrations was determined using the trypan blue test. PBMC, adjusted to $2 \times$ $26610^{6}$ cells $/ \mathrm{ml}$, incubated in twenty-four-well plates in the presence of RPMI 1640 medium, pure 267 gut model medium supernatant, SS1V1, SS2V1 and SS3V1 fermentation supernatant from B$268 \mathrm{GOS}$ and B. coagulans treated vessels, separately for $24 \mathrm{~h}$ at $37^{\circ} \mathrm{C}$ in an air- $\mathrm{CO}_{2}(19: 1)$ 269 atmosphere incubator. The tested supernatant amount of each treatment was $1 \%, 1.5 \%, 2 \%$, $3 \%, 4 \%, 5 \%$ and $10 \%(\mathrm{v} / \mathrm{v})$ of $2 \mathrm{ml}$ (final working volume). At the end of the incubation, cell numbers were counted using trypan blue test. According to viability results, only $1 \%(\mathrm{v} / \mathrm{v})$ was appropriate to use for different treatment supernatants.

\subsection{Cytokine stimulation and detection}

PBMCs were adjusted to yield $2 \times 10^{6}$ cells $/ \mathrm{ml}$. PBMCs were incubated in twenty-four-well plates in the presence of $1 \mathrm{mg} / \mathrm{ml}$ lipopolysaccharide (LPS; Sigma Aldrich Co. Ltd., Spain), $1 \%$ (v/v) pure gut model medium, $1 \mathrm{mg} / \mathrm{ml}$ LPS with $1 \%(\mathrm{v} / \mathrm{v})$ pure gut medium or $1 \mathrm{mg} / \mathrm{ml} \mathrm{LPS}$ with $1 \%(\mathrm{v} / \mathrm{v})$ supernatants from each steady state vessel of B-GOS and B. coagulans gut models for $24 \mathrm{~h}$ at $37^{\circ} \mathrm{C}$ in an air- $\mathrm{CO}_{2}(19: 1)$ atmosphere. At the end of the incubation, cell culture supernatants were collected and stored at $-20^{\circ} \mathrm{C}$ for later analysis of cytokine production.

280 Non-stimulated cultures were used as blank.

The production of IL-1 $\beta$, IL-6, IL-8, IL-10 and TNF- $\alpha$ were measured using BD ${ }^{\text {TM }}$ Cytometric and corresponding BD ${ }^{\mathrm{TM}}$ Cytometric Bead Array (CBA) Human Flex Set (BD Biosciences,

284 Oxford, UK) by BD Accuri ${ }^{\mathrm{TM}}$ C6 flow cytometer according to the manufacturer's instructions. $285 \mathrm{BD}^{\mathrm{TM}}$ CBA analysis software FCAP Array v3.0.1 (BD Biosciences, Oxford, UK) was used to perform data analysis. 


\subsection{Statistical analysis}

288 All statistical tests were performed with the use of SPSS version 18 (SPSS Inc, Chicago, IL).

289 Results are presented as means \pm SD.

290 Changes in specific bacterial groups, SCFA variation and cytokine production were assessed

291 between the three steady states using a one-way ANOVA. Significant differences were assessed

292 by post hoc Tukey HSD (Honestly Significant Difference) test. A value of $P<0.05$ indicates

293 there was a significant difference. In addition, for cytokine production, differences from LPS

294 control values were assessed using an independent $t$ test. Furthermore, independent $t$ test was

295 used to analyse the difference between B. coagulans and B-GOS treatments at SS3. A value of

$296 \quad P<0.05$ was used to indicate a significant difference.

\section{3. Results and Discussion}

298 Previous studies using animal models have found a negative impact of high fat diets on 299 gastrointestinal health; however, the mechanisms are still not clear (de La Serre et al., 2010;

300 Everard et al., 2013; Fava et al., 2013; Kim et al., 2012; Lam et al., 2012). Therefore an in vitro 301 gut model combined with an ex-vivo approach has been used to investigate the impact of high 302 fat mixture, comparing both prebiotics and probiotics, inoculated with faeces from elderly 303 persons.

\section{3.1. Viability results}

305 After 24h incubation of PBMCs with supernatants, PBMC viability was measured by trypan 306 blue. Viability was $91 \%$ with RPMI 1640 medium, $75 \%$ with $1 \%$ (v/v) pure gut model medium, $30770 \%$ and $62 \%$ with $1 \%(\mathrm{v} / \mathrm{v}) \mathrm{SS} 1 \mathrm{~V} 1$ and SS2V1 supernatants, $58 \%$ with $1 \%(\mathrm{v} / \mathrm{v})$ B. cogulans 308 SS3V1 supernatant, and 60\% with 1\% (v/v) B-GOS SS3V1 supernatant. Viability at other 309 concentrations $(1.5 \%, 2 \%, 3 \%, 4 \%, 5 \%$ and $10 \% \mathrm{v} / \mathrm{v})$ was lower than $40 \%$. Differences in viability may have an impact on cytokine production; therefore $1 \%(\mathrm{v} / \mathrm{v})$ supernatant was the 
most appropriate choice.

\section{3.2. In vitro effect of fat on bacterial composition, SCFA and cytokine production}

313 In the current study, using an in vitro approach, high fat supplementation was not observed to 314 lead to significant changes in bacterial composition (Figure 1 and Supplementary 2), cytokines induced by LPS ex vivo (Figure 2 and Supplementary 3) or organic acids (Figure 3 and

316 Supplementary 4). The results observed are in contrast to murine studies, where a reduction in

317 Bacteroides has been observed (Cani et al., 2007a; Cani et al., 2007i; Mozes, Bujnáková,

318 Sefcíková, \& Kmet, 2008; Neyrinck et al., 2011; Patrone et al., 2012). Additionally, a reduction

319 in bifidobacteria following a high fat diet has previously been observed (Cani et al., 2007a;

320 Cani et al., 2007i; Druart et al., 2013), however, these findings are not always reproducible. In

321 the studies, high fat diets had low carbohydrate (Cani et al., 2007a; Cani et al., 2007i; Druart

322 et al., 2013). Therefore, a decrease in bifidobacteria may stem from reduced carbohydrate

323 availability in such approaches. In animal models, a high fat diet has also been observed to

324 upregulate proinflammatory cytokines, such as TNF- $\alpha$ and IL-1 $\beta$, leading to inflammation and

325 a dysregulated immune response (Cani et al., 2007a; Cani et al., 2007i; Chen et al., 2011; Kim

326 et al., 2012; Lam et al., 2012; Neyrinck et al., 2011; Park et al., 2013). However, there are few

327 studies using human subjects to investigate effects of high fat diets on microbiota composition

328 and immune parameters. In the human study of Fava et al. (2013), subjects were fed a high saturated fat diet for 4 weeks (baseline), and then high monounsaturated fat diets for 24 weeks.

330 High monounsaturated fat diets did not have any significant effect on individual bacterial 331 numbers compared to baseline. Notably, this study recruited subjects who were at increased 332 risk of metabolic syndrome (MS) for a high fat diet treatment. It is suggested that the effect of 333 dietary fat on microbiota composition may be indirectly related to conjugated bile acids (bile salts). With increasing fat intake, hepatic production and release of bile acids from the gallbladder to small intestine, and the amount escaping enterohepatic recycling and entering 
into the gut is increased. Some members of gut microbiota can convert $7 \alpha$-dehydroxylate primary bile acids into secondary bile acids, which are potentially carcinogenic and related to colon cancer and gastrointestinal diseases (Ou, DeLany, Zhang, Sharma, \& O'Keefe, 2012; Ridlon, Kang, \& Hylemon, 2006). These bacteria normally represent a small proportion in the

340 gut and consist of species belonging to the genus Clostridium (Wells, Williams, Whitehead,

341 Heuman, \& Hylemon, 2003). Because, in the current study, only $2 \mathrm{~g} / 5 \mathrm{~L}$ bile salts were added to gut model medium and upper gut secretions are not mimicked, which might explain no significant microbial changes due to fat intake were observed. The combination with other in vitro gastric and small intestinal models could provide more valuable insights into the assessment of high fat diet on microbiota changes and immune function in future (Guerra et al., 2012; Payne, Zihler, Chassard, \& Lacroix, 2012).

Inflammation induced by a high fat diet may be related to microbiota changes in vivo. It has been suggested that alterations in the microbiota could lead to increased gut permeability following a high fat diet by decreasing mRNA expression of tight junction proteins including zona occludens-1 (Cani et al., 2008; Lam et al., 2012). With impaired gut barrier function these would lead to increased LPS translocation to plasma, which in turn leads to inflammation associated with metabolic disorder (Cani et al., 2007a; de La Serre et al., 2010; Kim et al., 2012). Chylomicrons, which transport dietary fat, also have a high affinity with LPS; and then can carry and move LPS from the gut lumen into the circulatory system (Ghoshal, Witta, Zhong, de Villiers, \& Eckhardt, 2009). In this study, because high fat mixtures did not change the microbiota composition and their consequent fermentation metabolites, immune markers were not influenced by high fat mixture fermentation supernatants in vitro. Results indicate that this high fat does not directly influence microbiota composition or immune response in vitro. Therefore a high fat diet did not directly serve as growth substrate for most microbiota. 


\subsection{In vitro effect of B-GOS on bacterial composition}

361 B-GOS is a novel trans-galactooligosaccharide mixture, produced by $\beta$-galactosidase activity of Bifidobacterium bifidum NCIMB 41171 on lactose (Tzortzis, Goulas, \& Gibson, 2005). According to Figure 1 and Supplementary 2, B-GOS supplementation with high fat at SS3 led to significantly increased numbers of lactobacilli/enterococci $(\mathrm{p}<0.01$, ANOVA), bifidobacteria ( $\mathrm{p}<0.001$, ANOVA), Eubacterium rectale - Clostridium coccoides $(\mathrm{p}<0.05$, ANOVA), Bacillus spp. ( $\mathrm{p}<0.001$, ANOVA) and total bacteria $(\mathrm{p}<0.05$, ANOVA) in three vessels of gut system compared to SS1 and SS2 (p<0.05, ANOVA). In addition, growth of Clostridium histolyticum group ( $<<0.001)$ and Bacteroides-Prevotella $\mathrm{spp} .(\mathrm{p}<0.001$, ANOVA) in the three vessels was also significantly inhibited by B-GOS supplementation with high fat at SS3 compared to SS1 and SS2. In the current study, under high fat conditions, B-GOS may confer a positive impact on the aged colon by conferring positive effects on beneficial bacteria at the expense of potentially negative bacteria. Similar results were also found in murine studies using fructo-oligosaccharides (Cani et al., 2007i; Respondek et al., 2013) and inulin (Druart et al., 2013) as prebiotics following a high fat diet. B-GOS has also been shown to confer positive effects on microbiota composition in healthy elderly persons (Vulevic et al., 2008; Vulevic et al., 2015) and overweight adults (Vulevic et al., 2013). The results of these human trials are in agreement with microbial variations in this in vitro study.

\subsection{In vitro effect of $B$. coagulans on bacterial composition}

According to Figure 1 and Supplementary 2, B. coagulans supplementation with high fat at SS3 significantly stimulated the growth of lactobacilli/enterococci in vessel $2(p=0.013$, ANOVA) and Bacillus spp. in all three vessels ( $\mathrm{p}<0.001$, ANOVA) when compared to SS1. $B$. coagulans supplementation also significantly decreased numbers of Clostridium histolyticum group in vessels 1 ( $\mathrm{p}=0.016$, ANOVA) and 3 ( $\mathrm{p}=0.021$, ANOVA) and numbers of Bacteroides- 
supplementation significantly stimulated the growth of lactobacilli/enterococci in vessels 1 $(\mathrm{p}=0.025$, ANOVA $)$ and $2(\mathrm{p}=0.003$, ANOVA $)$ when compared to SS2. Additionally, growth of bifidobacteria ( $\mathrm{p}<0.05$, ANOVA), Eubacterium rectale - Clostridium coccoides $(\mathrm{p}<0.05$, ANOVA) and Bacillus spp. ( $<<0.001$, ANOVA) were stimulated in all 3 vessels. In addition, the growth of Clostridium histolyticum group in the 3 vessels was significantly inhibited by $B$. coagulans supplementation compared to SS2 ( $<<0.05$, ANOVA).

B. coagulans could exert positive effects in the aged colon by modulating microbiota composition and organic acid production. Although B. coagulans has not been used to modulate the impact caused by high fat in previous studies, B. coagulans can modulate the microbiota with a significant increase in Bacillus spp., C. litsueburense and F. prausnitzii after 28-day supplementation in healthy elderly persons (Nyangale et al., 2014). In addition, metabolites produced by B. coagulans are beneficial to gastrointestinal health via production of nutrients such as organic acids, vitamin $\mathrm{K} 2$ and some B vitamins including folate and B12 (Jensen et al., 2010).

\subsection{In vitro effects of B-GOS and B. coagulans on SCFA and immune markers}

Supernatants from PBMCs cultured without gut model fermentation supernatant were used as controls (+/-). In the absence of LPS, there was no cytokine stimulation, with the exception of pure gut model medium that significantly stimulated production of IL-1 $\beta$, IL-6, IL-10 and TNF$\alpha$ compared to blank (Figure 2 and Supplementary 3). Pure gut model medium did not change production of IL-1 $\beta$, IL-6, IL-8, IL-10 and TNF- $\alpha$ induced by LPS ( $\mathrm{p}<0.05$, independent $\mathrm{t}$ test). High fat fermentation supernatants had no significant impact on tested cytokines induced by LPS (Figure 2 and Supplementary 3). Under high fat conditions, either B-GOS or B. coagulans

407 fermentation supernatants suppressed LPS-induced TNF- $\alpha$ production $(\mathrm{p}<0.05$, independent $\mathrm{t}$ 408 test) and enhanced LPS-induced IL-10 production ( $\mathrm{p}<0.05$, independent t-test). In vessel 3, B409 GOS significantly increased IL-10 compared to high fat fermentation supernatant ( $\mathrm{p}=0.049$, 
410 ANOVA). In vessels 2 and 3, under high fat condition B-GOS supernatant reduced IL-6

$411(\mathrm{p}<0.05$, independent $\mathrm{t}$ test $)$ and IL-1 $\beta(\mathrm{p}<0.05$, independent $\mathrm{t}$ test $)$ induced by LPS.

412 Under high fat conditions in vitro, either B-GOS or B. coagulans led to an anti-inflammatory

413 impact by down-regulating proinflammatory cytokines and enhancing anti-inflammatory

414 cytokines induced by LPS. The anti-inflammatory impact of B-GOS or B. coagulans have not

415 been tested before in animal models under high fat conditions. However, in a few murine

416 studies, some other prebiotics and probiotics may modulate immune responses by upregulating

417 anti-inflammatory cytokines and down-regulating proinflammatory cytokines (Cani et al.,

418 2007i). This has been the case for fructooligosaccharides, Bifidobacterium longum (Chen et al.,

419 2011), Lactobacillus spp. (Park et al., 2013).

420 In the current study, the anti-inflammatory impact of prebiotic or probiotics may be related to

421 fermentation metabolites. In either prebiotic or probiotic supplemented in vitro gut models,

422 acetate was the predominant fatty acid, followed by butyrate and propionate (Figure 3 and

423 Supplementary 4). Compared to SS1, B. coagulans with high fat at SS3 stimulated production

424 of acetate in vessel 3 ( $\mathrm{p}=0.035$, ANOVA). Compared to SS2, B. coagulans significantly

425 stimulated acetate ( $<<0.05$, ANOVA) and butyrate $(p<0.05$, ANOVA) in all three vessels.

426 Compared to SS1, B-GOS with high fat at SS3 significantly stimulated the production of

427 acetate in all three vessels ( $p<0.01$, ANOVA) and butyrate in vessels 2 and 3 ( $p<0.05$, ANOVA).

428 Compared to SS2, B-GOS supplementation significantly stimulated acetate ( $<<0.01$, ANOVA)

429 and butyrate $(\mathrm{p}<0.01$, ANOVA $)$ in the three vessels.

430 TNF- $\alpha$ production induced by stimuli in vitro could be inhibited by SCFAs, especially butyrate

431 and acetate (Liu et al., 2012; Segain et al., 2000; Usami et al., 2008; Vinolo et al., 2011).

432 Butyrate could suppress proinflammatory cytokine production by inhibiting LPS-induced

433 nuclear factor-кB (NF-kB) activation in vitro (Liu et al., 2012; Segain et al., 2000; Usami et al.,

434 2008; Vinolo et al., 2011). Acetate could down-regulate proinflammatory cytokine production 
by lipoxygenase activation without inhibition of NF-אB (Usami et al., 2008). A variation in TNF- $\alpha$ is in line with SCFA production by B-GOS or B. coagulans under high fat conditions.

437 Other fermentation metabolites show an inhibitory impact on TNF- $\alpha$ by blocking NF-кB 438 activation, such as vitamins and unknown fermentation end-products produced by gut 439 microbiota (van Hylckama Vlieg, Veiga, Zhang, Derrien, \& Zhao, 2011), although they were 440 not determined in the current study.

441 IL-10 is an important anti-inflammatory cytokine that could counteract the production of 442 proinflammatory cytokines, such as TNF- $\alpha$ (Cavaglieri et al., 2003; Saemann et al., 2000). In 443 the current study, up-regulation of IL-10 indicated that prebiotics or probiotics could positively 444 modulate the immune response in elderly under high fat conditions, which may be associated 445 with their fermentation end products. A few studies have shown that butyrate and acetate could increase IL-10 production in vitro (Cavaglieri et al., 2003; Liu et al., 2012; Segain et al., 2000). IL-6 is mostly considered as a proinflammatory cytokine and proinflammatory activities of IL6 are mediated by trans-signaling (Scheller, Chalaris, Schmidt-Arras, \& Rose-John, 2011). The 449 inhibitory effect of B-GOS on IL-6 has been seen previously. In the study of Vulevic et al. 450 (2008), daily intake of $5.5 \mathrm{~g}$ BiMuno ${ }^{\circledR}$ mixture (2.64g B-GOS) by healthy elderly volunteers was shown to decrease IL-6 production.

452 In the current study, under high fat conditions, either B. coagulans or B-GOS could improve 453 the gut heath and modulate immune markers. However, when comparing B. coagulans and B454 GOS supplementations at SS3, B-GOS significantly stimulated the growth of 455 lactobacilli/enterococci $(\mathrm{p}<0.01$, independent $\mathrm{t}$ test $)$, bifidobacteria $(\mathrm{p}<0.001$, independent $\mathrm{t}$ test $)$ and Eubacterium rectale - Clostridium coccoides $(\mathrm{p}<0.05$, independent $\mathrm{t}$ test) to a greater extent than $B$. coagulans in the three vessels of gut system $(\mathrm{p}<0.05$, independent $\mathrm{t}$ test $)$; while B. coagulans significantly increased numbers of Bacillus spp. in vessels 1 and 2 to a greater extent than B-GOS ( $p<0.05$, independent $t$ test). In addition, B-GOS led to significantly greater 
460 stimulation of acetate in all three vessels of gut system ( $\mathrm{p}<0.05$, independent $\mathrm{t}$ test). Compared 461 to B. coagulans fermentation supernatant, B-GOS under high fat condition had lower levels of

462 IL-6 ( $p<0.05$, independent $t$ test). Therefore, the effects of $B$. coagulans could be much 463 enhanced and protected by mixed with prebiotics. The impacts of $B$. coagulans have been 464 shown to be enhanced with the addition of potentially prebiotic $\beta$-glucans (Arena et al., 2016) 465 and inulin (Abhari, Shekarforoush, Sajedianfard, Hosseinzadeh, \& Nazifi, 2015). The anti466 inflammatory impacts can be enhanced by synergistic effects of combination of $B$. coagulans 467 and $\beta$-glucans (Arena et al., 2016). Inulin could enhance the survival and growth of $B$. 468 coagulans, with the number of spores significantly higher in synbiotic fed rats compared to 469 probiotic fed (Abhari et al., 2015).

470 In conclusion, high fat addition did not significantly influence the composition of bacteria and 471 immune responses in vitro. However under high fat conditions, either B. coagulans or B-GOS may act as health-promoting food supplements to enhance the aged gastrointestinal tract by targeting specific bacterial groups, increasing saccharolytic fermentation and modulating 474 immune markers. Human intervention research would further clarify pre/probiotic effects 475 during high fat diets on elderly gut microbiota and mechanisms of microbial and immune 476 response modulation.

\section{Acknowledgments}

478 The authors would like to thank Dr. George Tzortzis for provision of the B-GOS used within 479 this study.

\section{References}

Abhari, K., Shekarforoush, S. S., Sajedianfard, J., Hosseinzadeh, S., \& Nazifi, S. (2015). The effects of probiotic, prebiotic and synbiotic diets containing Bacillus coagulans and inulin on rat intestinal microbiota. Iran J Vet Res, 16(3), 267-273.

Arena, M. P., Russo, P., Capozzi, V., Rascón, A., Felis, G. E., Spano, G., \& Fiocco, D. (2016). Combinations of cereal $\beta$-glucans and probiotics can enhance the anti-inflammatory activity on host cells by a synergistic effect. 
Bates, B., Lennox, A., Prentice, A., Bates, C., \& Swan, G. (2012). National Diet and Nutrition Survey: Headline results from Years 1, 2 and 3 (combined) of the rolling programme (2008/2009 - 2010/11). https://www.gov.uk/government/statistics/national-diet-and-nutrition-survey-headline-results-fromyears-1-2-and-3-combined-of-the-rolling-programme-200809-201011 Accessed 12th August 2012

Biagi, E., Nylund, L., Candela, M., Ostan, R., Bucci, L., Pini, E., Nikkila, J., Monti, D., Satokari, R., Franceschi, C., Brigidi, P., \& De Vos, W. (2010). Through ageing, and beyond: gut microbiota and inflammatory status in seniors and centenarians. PloS One, 5(5), e10667.

Bruunsgaard, H., Pedersen, A. N., Schroll, M., Skinhoj, P., \& Pedersen, B. K. (2001). Decreased natural killer cell activity is associated with atherosclerosis in elderly humans. Experimental Gerontology, 37(1), 127-136.

Butcher, S. K., Chahal, H., Nayak, L., Sinclair, A., Henriquez, N. V., Sapey, E., O'Mahony, D., \& Lord, J. M. (2001). Senescence in innate immune responses: reduced neutrophil phagocytic capacity and CD16 expression in elderly humans. Journal of Leukocyte Biology, 70(6), 881-886.

Candela, M., Biagi, E., Turroni, S., Rampelli, S., \& Brigidi, P. (2015). Gut microbiome and longevity, adaptation to the extreme limits of human lifespan. Annals of Nutrition and Metabolism, 64, 44-44.

Cani, P. D., Amar, J., Iglesias, M. A., Poggi, M., Knauf, C., Bastelica, D., Neyrinck, A. M., Fava, F., Tuohy, K. M., Chabo, C., Waget, A., Delmee, E., Cousin, B., Sulpice, T., Chamontin, B., Ferrieres, J., Tanti, J. F., Gibson, G. R., Casteilla, L., Delzenne, N. M., Alessi, M. C., \& Burcelin, R. (2007a). Metabolic endotoxemia initiates obesity and insulin resistance. Diabetes., 56(7), 1761-1772.

Cani, P. D., Bibiloni, R., Knauf, C., Waget, A., Neyrinck, A. M., Delzenne, N. M., \& Burcelin, R. (2008). Changes in gut microbiota control metabolic endotoxemia-induced inflammation in high-fat diet-induced obesity and diabetes in mice. Diabetes., 57(6), 1470-1481.

Cani, P. D., Neyrinck, A. M., Fava, F., Knauf, C., Burcelin, R. G., Tuohy, K. M., Gibson, G. R., \& Delzenne, N. M. (2007i). Selective increases of bifidobacteria in gut microflora improve high-fat-diet-induced diabetes in mice through a mechanism associated with endotoxaemia. Diabetologia., 50(11), 2374-2383.

Castell, D. O. (1988). Eating and swallowing disorders in the elderly. Practical gastroenterology., 12, 32-43.

Cavaglieri, C. R., Nishiyama, A., Fernandes, L. C., Curi, R., Miles, E. A., \& Calder, P. C. (2003). Differential effects of short-chain fatty acids on proliferation and production of pro- and anti-inflammatory cytokines by cultured lymphocytes. Life sciences., 73(13), 1683-1690.

Chen, J. J., Wang, R., Li, X. F., \& Wang, R. L. (2011). Bifidobacterium longum supplementation improved high-fatfed-induced metabolic syndrome and promoted intestinal Reg I gene expression. Experimental Biology and Medicine (Maywood, N.J.), 236(7), 823-831.

Claesson, M. J., Cusack, S., O'Sullivan, O., Greene-Diniz, R., de Weerd, H., Flannery, E., Marchesi, J. R., Falush, D., Dinan, T., Fitzgerald, G., Stanton, C., van Sinderen, D., O'Connor, M., Harnedy, N., O'Connor, K., Henry, C., O'Mahony, D., Fitzgerald, A. P., Shanahan, F., Twomey, C., Hill, C., Ross, R. P., \& O'Toole, P. W. (2011). Composition, variability, and temporal stability of the intestinal microbiota of the elderly. Proceedings of the National Academy of Sciences of the United States of America, 108 Suppl 1, 4586-4591.

Daims, H., Bruhl, A., Amann, R., Schleifer, K. H., \& Wagner, M. (1999). The domain-specific probe EUB338 is insufficient for the detection of all bacteria: development and evaluation of a more comprehensive probe set. Systematic and Applied Microbiology, 22(3), 434-444.

Daims, H., Stoecker, K., \& Wagner, M. (2005). Fluorescence in situ hybridization for the detection of prokaryotes. In A. M. Osborn \& C. J. Smith (Eds.), Molecular microbial ecology (pp. 213-239). Abingdon, UK: Garland Science.

de La Serre, C. B., Ellis, C. L., Lee, J., Hartman, A. L., Rutledge, J. C., \& Raybould, H. E. (2010). Propensity to highfat diet-induced obesity in rats is associated with changes in the gut microbiota and gut inflammation. American journal of physiology. Gastrointestinal and liver physiology., 299(2), G440-448.

Druart, C., Neyrinck, A. M., Dewulf, E. M., De Backer, F. C., Possemiers, S., Van de Wiele, T., Moens, F., De Vuyst, L., Cani, P. D., Larondelle, Y., \& Delzenne, N. M. (2013). Implication of fermentable carbohydrates targeting the gut microbiota on conjugated linoleic acid production in high-fat-fed mice. The British journal of nutrition., 110(6), 998-1011.

Endres, J. R., Clewell, A., Jade, K. A., Farber, T., Hauswirth, J., \& Schauss, A. G. (2009). Safety assessment of a proprietary preparation of a novel Probiotic, Bacillus coagulans, as a food ingredient. Food and Chemical Toxicology, 47(6), 1231-1238.

Everard, A., Belzer, C., Geurts, L., Ouwerkerk, J. P., Druart, C., Bindels, L. B., Guiot, Y., Derrien, M., Muccioli, G. G., Delzenne, N. M., de Vos, W. M., \& Cani, P. D. (2013). Cross-talk between Akkermansia muciniphila and intestinal epithelium controls diet-induced obesity. Proceedings of the National Academy of Sciences of the United States of America, 110(22), 9066-9071. 
Fava, F., Gitau, R., Griffin, B. A., Gibson, G. R., Tuohy, K. M., \& Lovegrove, J. A. (2013). The type and quantity of dietary fat and carbohydrate alter faecal microbiome and short-chain fatty acid excretion in a metabolic syndrome 'at-risk' population. International Journal of Obesity (2005), 37(2), 216-223.

Franks, A. H., Harmsen, H. J., Raangs, G. C., Jansen, G. J., Schut, F., \& Welling, G. W. (1998). Variations of bacterial populations in human feces measured by fluorescent in situ hybridization with group-specific 16S rRNAtargeted oligonucleotide probes. Applied and Environmental Microbiology, 64(9), 3336-3345.

Gavini, F., Cayuela, C., Antoine, J.-M., Lecoq, C., Lefebvre, B., Membre', J.-M., \& Neut, C. (2001). Differences in the distribution of bifidobacterial and enterobacterial species in human faecal microbiota of three (children, adults, elderly) age groups. Microbial Ecology in Health and Disease, 13, 40-45.

Ghoshal, S., Witta, J., Zhong, J., de Villiers, W., \& Eckhardt, E. (2009). Chylomicrons promote intestinal absorption of lipopolysaccharides. Journal of Lipid Research, 50(1), 90-97.

Goodwin, J. S. (1995). Decreased immunity and increased morbidity in the elderly. Nutrition Reviews, 53(4 Pt 2), S41-44; discussion S44-46.

Guerra, A., Etienne-Mesmin, L., Livrelli, V., Denis, S., Blanquet-Diot, S., \& Alric, M. (2012). Relevance and challenges in modeling human gastric and small intestinal digestion. Trends in Biotechnology, 30(11), 591-600.

Harmsen, H. J., Elfferich, P., Schut, F., \& Welling, G. W. (1999). A $16 \mathrm{~S}$ rRNA-targeted probe for detection of lactobacilli and enterococci in faecal samples by fluorescent in situ hybridization. Microbial Ecology in Health and Disease, 11(1), 3-12.

Harmsen, H. J., Wildeboer-Veloo, A. C., Grijpstra, J., Knol, J., Degener, J. E., \& Welling, G. W. (2000). Development of $16 \mathrm{~S}$ rRNA-based probes for the Coriobacterium group and the Atopobium cluster and their application for enumeration of Coriobacteriaceae in human feces from volunteers of different age groups. Applied and Environmental Microbiology, 66(10), 4523-4527.

Honda, H., Gibson, G. R., Farmer, S., Keller, D., \& McCartney, A. L. (2011). Use of a continuous culture fermentation system to investigate the effect of GanedenBC30 (Bacillus coagulans GBI-30, 6086) supplementation on pathogen survival in the human gut microbiota. Anaerobe, 17(1), 36-42.

Hopkins, M. J., \& Macfarlane, G. T. (2002). Changes in predominant bacterial populations in human faeces with age and with Clostridium difficile infection. Journal of Medical Microbiology, 51(5), 448-454.

Hopkins, M. J., Sharp, R., \& Macfarlane, G. T. (2001). Age and disease related changes in intestinal bacterial populations assessed by cell culture, 16S rRNA abundance, and community cellular fatty acid profiles. Gut, 48(2), 198-205.

Hopkins, M. J., Sharp, R., \& Macfarlane, G. T. (2002). Variation in human intestinal microbiota with age. Digestive and Liver Disease, 34 Supp/ 2, S12-18.

Jensen, G. S., Benson, K. F., Carter, S. G., \& Endres, J. R. (2010). GanedenBC30 cell wall and metabolites: antiinflammatory and immune modulating effects in vitro. BMC Immunology, 11, 15.

Karlsson, S., Persson, M., \& Carlsson, G. E. (1991). Mandibular movement and velocity in relation to state of dentition and age. Journal of Oral Rehabilitation, 18(1), 1-8.

Kim, K. A., Gu, W., Lee, I. A., Joh, E. H., \& Kim, D. H. (2012). High fat diet-induced gut microbiota exacerbates inflammation and obesity in mice via the TLR4 signaling pathway. PloS One, 7(10), e47713.

Lam, Y. Y., Ha, C. W., Campbell, C. R., Mitchell, A. J., Dinudom, A., Oscarsson, J., Cook, D. I., Hunt, N. H., Caterson, I. D., Holmes, A. J., \& Storlien, L. H. (2012). Increased gut permeability and microbiota change associate with mesenteric fat inflammation and metabolic dysfunction in diet-induced obese mice. PloS One, 7(3), e34233.

Langendijk, P. S., Schut, F., Jansen, G. J., Raangs, G. C., Kamphuis, G. R., Wilkinson, M. H., \& Welling, G. W. (1995). Quantitative fluorescence in situ hybridization of Bifidobacterium spp. with genus-specific 16S rRNAtargeted probes and its application in fecal samples. Applied and Environmental Microbiology, 61(8), 3069-3075.

Liu, T., Li, J., Liu, Y., Xiao, N., Suo, H., Xie, K., Yang, C., \& Wu, C. (2012). Short-chain fatty acids suppress lipopolysaccharide-induced production of nitric oxide and proinflammatory cytokines through inhibition of NF-kappaB pathway in RAW264.7 cells. Inflammation, 35(5), 1676-1684.

Macfarlane, G. T., Macfarlane, S., \& Gibson, G. R. (1998). Validation of a Three-Stage Compound Continuous Culture System for Investigating the Effect of Retention Time on the Ecology and Metabolism of Bacteria in the Human Colon. Microbial Ecology, 35(2), 180-187.

Manz, W., Amann, R., Ludwig, W., Vancanneyt, M., \& Schleifer, K. H. (1996). Application of a suite of $16 \mathrm{~S}$ rRNAspecific oligonucleotide probes designed to investigate bacteria of the phylum Cytophaga-FlavobacterBacteroides in the natural environment. Microbiology, 142 ( Pt 5), 1097-1106.

Mitsuoka, T. (1992). Intestinal flora and aging. Nutrition Reviews, 50(12), 438-446. 
Mozes, S., Bujnáková, D., Sefcíková, Z., \& Kmet, V. (2008). Developmental changes of gut microflora and enzyme activity in rat pups exposed to fat-rich diet. Obesity (Silver Spring), 16(12), 2610-2615.

Mueller, S., Saunier, K., Hanisch, C., Norin, E., Alm, L., Midtvedt, T., Cresci, A., Silvi, S., Orpianesi, C., Verdenelli, M. C., Clavel, T., Koebnick, C., Zunft, H. J., Dore, J., \& Blaut, M. (2006). Differences in fecal microbiota in different European study populations in relation to age, gender, and country: a cross-sectional study. Applied and Environmental Microbiology, 72(2), 1027-1033.

Neyrinck, A. M., Possemiers, S., Druart, C., Van de Wiele, T., De Backer, F., Cani, P. D., Larondelle, Y., \& Delzenne, N. M. (2011). Prebiotic effects of wheat arabinoxylan related to the increase in bifidobacteria, Roseburia and Bacteroides/Prevotella in diet-induced obese mice. PloS One, 6(6), e20944.

Nyangale, E. P., Farmer, S., Keller, D., Chernoff, D., \& Gibson, G. R. (2014). Effect of prebiotics on the fecal microbiota of elderly volunteers after dietary supplementation of Bacillus coagulans GBI-30, 6086. Anaerobe, 30, 75-81.

Ou, J., DeLany, J. P., Zhang, M., Sharma, S., \& O'Keefe, S. J. (2012). Association between low colonic short-chain fatty acids and high bile acids in high colon cancer risk populations. Nutrition and Cancer, 64(1), 34-40.

Park, D. Y., Ahn, Y. T., Park, S. H., Huh, C. S., Yoo, S. R., Yu, R., Sung, M. K., McGregor, R. A., \& Choi, M. S. (2013). Supplementation of Lactobacillus curvatus HY7601 and Lactobacillus plantarum KY1032 in diet-induced obese mice is associated with gut microbial changes and reduction in obesity. PloS One, 8(3), e59470.

Patrone, V., Ferrari, S., Lizier, M., Lucchini, F., Minuti, A., Tondelli, B., Trevisi, E., Rossi, F., \& Callegari, M. L. (2012). Short-term modifications in the distal gut microbiota of weaning mice induced by a high-fat diet. Microbiology, 158(Pt 4), 983-992.

Payne, A. N., Zihler, A., Chassard, C., \& Lacroix, C. (2012). Advances and perspectives in in vitro human gut fermentation modeling. Trends in Biotechnology, 30(1), 17-25.

Puddu, A., Sanguineti, R., Montecucco, F., \& Viviani, G. L. (2014). Evidence for the gut microbiota short-chain fatty acids as key pathophysiological molecules improving diabetes. Mediators Inflamm, 2014, 162021.

Pyndt Jørgensen, B., Hansen, J. T., Krych, L., Larsen, C., Klein, A. B., Nielsen, D. S., Josefsen, K., Hansen, A. K., \& Sorensen, D. B. (2014). A possible link between food and mood: dietary impact on gut microbiota and behavior in BALB/c mice. PloS One, 9(8), e103398.

Rampelli, S., Candela, M., Severgnini, M., Biagi, E., Turroni, S., Roselli, M., Carnevali, P., Donini, L., \& Brigidi, P. (2013a). A probiotics-containing biscuit modulates the intestinal microbiota in the elderly. J Nutr Health Aging, 17(2), 166-172.

Rampelli, S., Candela, M., Turroni, S., Biagi, E., Collino, S., Franceschi, C., O'Toole, P. W., \& Brigidi, P. (2013c). Functional metagenomic profiling of intestinal microbiome in extreme ageing. Aging (Albany NY), 5(12), 902-912.

Rampelli, S., Candela, M., Turroni, S., Biagi, E., Pflueger, M., Wolters, M., Ahrens, W., \& Brigidi, P. (2016). Microbiota and lifestyle interactions through the lifespan. Trends in Food Science \& Technology, 57, Part $B, 265-272$.

Remond, D., Shahar, D. R., Gille, D., Pinto, P., Kachal, J., Peyron, M. A., Dos Santos, C. N., Walther, B., Bordoni, A., Dupont, D., Tomas-Cobos, L., \& Vergeres, G. (2015). Understanding the gastrointestinal tract of the elderly to develop dietary solutions that prevent malnutrition. Oncotarget, 6(16), 13858-13898.

Respondek, F., Gerard, P., Bossis, M., Boschat, L., Bruneau, A., Rabot, S., Wagner, A., \& Martin, J. C. (2013). Shortchain fructo-oligosaccharides modulate intestinal microbiota and metabolic parameters of humanized gnotobiotic diet induced obesity mice. PloS One, 8(8), e71026.

Richardson, A. J., Calder, A. G., Stewart, C. S., \& Smith, A. (1989). Simultaneous determination of volatile and non-volatile acidic fermentation products of anaerobes by capillary gas chromatography. Letters in applied microbiology., 9(1), 5-8.

Ridlon, J. M., Kang, D. J., \& Hylemon, P. B. (2006). Bile salt biotransformations by human intestinal bacteria. Journal of Lipid Research, 47(2), 241-259.

Saemann, M. D., Bohmig, G. A., Osterreicher, C. H., Burtscher, H., Parolini, O., Diakos, C., Stockl, J., Horl, W. H., \& Zlabinger, G. J. (2000). Anti-inflammatory effects of sodium butyrate on human monocytes: potent inhibition of IL-12 and up-regulation of IL-10 production. FASEB Journal, 14(15), 2380-2382.

Sakai, K., \& Ezaki, Y. (2006). Open L-lactic acid fermentation of food refuse using thermophilic Bacillus coagulans and fluorescence in situ hybridization analysis of microflora. Journal of Bioscience and Bioengineering, 101(6), 457-463.

Salvetti, E., Orru, L., Capozzi, V., Martina, A., Lamontanara, A., Keller, D., Cash, H., Felis, G. E., Cattivelli, L., Torriani, S., \& Spano, G. (2016). Integrate genome-based assessment of safety for probiotic strains: Bacillus coagulans GBI-30, 6086 as a case study. Applied Microbiology and Biotechnology, 100(10), 4595-4605.

Scheller, J., Chalaris, A., Schmidt-Arras, D., \& Rose-John, S. (2011). The pro- and anti-inflammatory properties of 
683

684

685

686

687

688

689

690

691

692

the cytokine interleukin-6. Biochimica et Biophysica Acta, 1813(5), 878-888.

Schiffrin, E. J., Morley, J. E., Donnet-Hughes, A., \& Guigoz, Y. (2010). The inflammatory status of the elderly: the intestinal contribution. Mutation Research, 690(1-2), 50-56.

Segain, J. P., Raingeard de la Bletiere, D., Bourreille, A., Leray, V., Gervois, N., Rosales, C., Ferrier, L., Bonnet, C., Blottiere, H. M., \& Galmiche, J. P. (2000). Butyrate inhibits inflammatory responses through NFkappaB inhibition: implications for Crohn's disease. Gut, 47(3), 397-403.

Tzortzis, G., Goulas, A. K., \& Gibson, G. R. (2005). Synthesis of prebiotic galactooligosaccharides using whole cells of a novel strain, Bifidobacterium bifidum NCIMB 41171. Applied and Environmental Microbiology, 68(3), 412-416.

Usami, M., Kishimoto, K., Ohata, A., Miyoshi, M., Aoyama, M., Fueda, Y., \& Kotani, J. (2008). Butyrate and trichostatin A attenuate nuclear factor kappaB activation and tumor necrosis factor alpha secretion and increase prostaglandin E2 secretion in human peripheral blood mononuclear cells. Nutrition Research, 28(5), 321-328.

van Hylckama Vlieg, J. E., Veiga, P., Zhang, C., Derrien, M., \& Zhao, L. (2011). Impact of microbial transformation of food on health - from fermented foods to fermentation in the gastro-intestinal tract. Current Opinion in Biotechnology, 22(2), 211-219.

Vinolo, M. A., Rodrigues, H. G., Hatanaka, E., Sato, F. T., Sampaio, S. C., \& Curi, R. (2011). Suppressive effect of short-chain fatty acids on production of proinflammatory mediators by neutrophils. The Journal of Nutritional Biochemistry, 22(9), 849-855.

Vulevic, J., Drakoularakou, A., Yaqoob, P., Tzortzis, G., \& Gibson, G. R. (2008). Modulation of the fecal microflora profile and immune function by a novel trans-galactooligosaccharide mixture (B-GOS) in healthy elderly volunteers. The American journal of clinical nutrition., 88(5), 1438-1446.

Vulevic, J., Juric, A., Tzortzis, G., \& Gibson, G. R. (2013). A mixture of trans-galactooligosaccharides reduces markers of metabolic syndrome and modulates the fecal microbiota and immune function of overweight adults. The Journal of Nutrition, 143(3), 324-331.

Vulevic, J., Juric, A., Walton, G. E., Claus, S. P., Tzortzis, G., Toward, R. E., \& Gibson, G. R. (2015). Influence of galacto-oligosaccharide mixture (B-GOS) on gut microbiota, immune parameters and metabonomics in elderly persons. Br J Nutr, 114(4), 586-595.

Wells, J. E., Williams, K. B., Whitehead, T. R., Heuman, D. M., \& Hylemon, P. B. (2003). Development and application of a polymerase chain reaction assay for the detection and enumeration of bile acid 7alphadehydroxylating bacteria in human feces. Clinica Chimica Acta, 331(1-2), 127-134.

WHO. (2014). Facts about ageing. http://www.who.int/ageing/about/facts/en/ Accessed 30th January 2015

Woodmansey, E. J., McMurdo, M. E., Macfarlane, G. T., \& Macfarlane, S. (2004). Comparison of compositions and metabolic activities of fecal microbiotas in young adults and in antibiotic-treated and non-antibiotictreated elderly subjects. Applied and Environmental Microbiology, 70(10), 6113-6122.

Table 1 Feeding materials added to three-stage continuous culture daily at stage SS2 and SS3

Amount (daily) 
Sunflower oil

Olive oil

$1.33 \mathrm{~g}$

Coconut oil

$0.83 \mathrm{~g}$

glucose

$0.394 \mathrm{~g}$

galactose

$0.017 \mathrm{~g}$

lactose

$0.348 \mathrm{~g}$

SS3-high fat and prebiotic treatment*

B-GOS

$1.063 \mathrm{~g}$

Protein

$0.003 \mathrm{~g}$

Ash

$0.008 \mathrm{~g}$

Moisture

$0.661 \mathrm{~g}$

SS3-high fat and probiotic

B. coagulans

$3.3 \times 10^{8} \mathrm{cfu}$

\section{treatment*}

699 At stage SS3, same amount of high fat treatment were added to culture daily as SS2. The same

700 amounts of glucose, galactose and lactose were also added to non-prebiotic fed culture daily. 
Table 2 Hybridisation and washing conditions for oligonucleotide probes

\begin{tabular}{|c|c|c|c|c|c|}
\hline Probe name & Sequence (5' to 3') & $\begin{array}{l}\text { Hybridisation } \\
\text { pre-treatment }\end{array}$ & $\begin{array}{l}\text { Formamide (\%) in } \\
\text { hybridisation } \\
\text { buffer }\end{array}$ & $\begin{array}{l}\text { Hybridisation- } \\
\text { washing temperature } \\
\left({ }^{\circ} \mathrm{C}\right)\end{array}$ & Reference \\
\hline Ato 291 & GGTCGGTCTCTCAACCC & Lysozyme & 0 & $50-50$ & (Harmsen et al., 2000) \\
\hline Lab 158 & GGTATTAGCAYCTGTTTCCA & Lysozyme & 0 & $50-50$ & (Harmsen et al., 1999) \\
\hline Bif 164 & CATCCGGCATTACCACCC & Lysozyme & 0 & $50-50$ & (Langendijk et al., 1995) \\
\hline Erec 482 & GCTTCTTAGTCARGTACCG & None & 0 & $50-50$ & (Franks et al., 1998) \\
\hline Chis 150 & TTATGCGGTATTAATCTYCCTTT & None & 0 & $50-50$ & (Franks et al., 1998) \\
\hline Bcoa 191 & GCCGCCTTTCCTTTTTCCTCC & Lysozyme & 20 & $46-48$ & (Sakai \& Ezaki, 2006) \\
\hline Bac 303 & CCAATGTGGGGGACCTT & None & 0 & $46-48$ & (Manz et al., 1996) \\
\hline EUB338* & GCTGCCTCCCGTAGGAGT & None & 35 & $46-48$ & (Daims et al., 1999) \\
\hline EUB338II* & GCAGCCACCCGTAGGTGT & None & 35 & $46-48$ & (Daims et al., 1999) \\
\hline EUB338III* & GCTGCCACCCGTAGGTGT & None & 35 & $46-48$ & (Daims et al., 1999) \\
\hline
\end{tabular}

* These probes were used together in equimolar concentrations (all at $50 \mathrm{ng} \mu \mathrm{l}^{-1}$ ) 
Table 3 Bacterial numbers in three different vessels (Vessel 1, Vessel 2, Vessel 3) of in vitro

colonic models before adding any treatment at steady state (SS) 1, after adding high fat

mixture at SS2, and after adding high fat mixture with B-GOS/ B. coagulans treatment at

SS3.

\begin{tabular}{|c|c|c|c|c|c|c|c|}
\hline \multirow{2}{*}{ Group } & & \multicolumn{3}{|c|}{ B-GOS } & \multicolumn{3}{|c|}{ B. coagulans } \\
\hline & & Vessel 1 & Vessel 2 & Vessel 3 & Vessel 1 & Vessel 2 & Vessel 3 \\
\hline \multicolumn{8}{|c|}{$\log _{10}$ bacteria number $/ \mathrm{ml}$} \\
\hline \multirow[t]{3}{*}{ Lab 158} & SS1 & $8.69 \pm 0.10 \mathrm{a}$ & $8.43 \pm 0.14 \mathrm{a}$ & $8.11 \pm 0.12 \mathrm{a}$ & $8.71 \pm 0.06 \mathrm{ab}$ & $8.38 \pm 0.07 \mathrm{a}$ & $8.12 \pm 0.11$ \\
\hline & SS2 & $8.56 \pm 0.14 \mathrm{a}$ & $8.33 \pm 0.09 \mathrm{a}$ & $8.04 \pm 0.12 \mathrm{a}$ & $8.57 \pm 0.08 \mathrm{a}$ & $8.32 \pm 0.02 \mathrm{a}$ & $8.07 \pm 0.09$ \\
\hline & SS3 & $9.21 \pm 0.08 b^{*}$ & $9.03 \pm 0.05 b^{*}$ & $8.79 \pm 0.09 b^{*}$ & $8.81 \pm 0.06 b^{*}$ & $8.58 \pm 0.04 b^{*}$ & $8.24 \pm 0.06^{*}$ \\
\hline \multirow[t]{3}{*}{ Bif 164} & SS1 & $8.76 \pm 0.12 \mathrm{a}$ & $8.68 \pm 0.15 a$ & $8.51 \pm 0.13 \mathrm{a}$ & $8.83 \pm 0.08 \mathrm{ab}$ & $8.72 \pm 0.14 \mathrm{ab}$ & $8.53 \pm 0.07 \mathrm{ab}$ \\
\hline & SS2 & $8.63 \pm 0.13 \mathrm{a}$ & $8.55 \pm 0.09 a$ & $8.39 \pm 0 .($ & $8.67 \pm 0.07 \mathrm{a}$ & $8.52 \pm 0.09 \mathrm{a}$ & $8.35 \pm 0.06 \mathrm{a}$ \\
\hline & SS3 & $9.91 \pm 0.05 b^{*}$ & $9.80 \pm 0.04 b^{*}$ & $9.69 \pm 0.04 b^{*}$ & $9.05 \pm 0.09 b^{*}$ & $8.85 \pm 0.06 b^{*}$ & $8.67 \pm 0.11 b^{*}$ \\
\hline \multirow[t]{3}{*}{ Erec 482} & SS1 & $9.38 \pm 0.06 a$ & $9.23 \pm 0.07 \mathrm{a}$ & $9.13 \pm 0.07 \mathrm{a}$ & $9.43 \pm 0.03 \mathrm{ab}$ & $9.32 \pm 0.08 \mathrm{ab}$ & $9.15 \pm 0.05 \mathrm{ab}$ \\
\hline & $\mathrm{SS} 2$ & $9.12 \pm 0.15 \mathrm{a}$ & $8.91 \pm 0.11 \mathrm{a}$ & $8.73 \pm 0.05 a$ & $9.13 \pm 0.15 a$ & $8.90 \pm 0.10 \mathrm{a}$ & $8.68 \pm$ \\
\hline & SS3 & $9.72 \pm 0.06 b *$ & $9.57 \pm 0.09 b^{*}$ & $9.47 \pm($ & $9.49 \pm 0.05 b^{*}$ & $9.22 \pm 0.07 b^{*}$ & $9.12 \pm 0$ \\
\hline \multirow[t]{3}{*}{ Chis 150} & SS1 & $7.35 \pm 0.08 b$ & $7.20 \pm 0.06 b$ & $6.63 \pm 0.07 b$ & $7.25 \pm 0.03 b$ & $6.99 \pm 0.19 \mathrm{ab}$ & $6.54=$ \\
\hline & $\mathrm{SS} 2$ & $7.41 \pm 0.06 b$ & $7.35 \pm 0.09 b$ & $7.03 \pm$ & $7.42 \pm$ & $7.36 \pm 0.11 b$ & $6.99 \pm$ \\
\hline & SS3 & $6.47 \pm 0.09 a^{*}$ & $6.35 \pm 0.09 a^{*}$ & $6.13 \pm 0$ & $6.91 \pm 0.10 a^{*}$ & $6.83 \pm 0.04 \mathrm{a}^{*}$ & $6.36=$ \\
\hline \multirow[t]{3}{*}{ Bcoa 191} & SS1 & & $6.71 \pm 0.10 \mathrm{a}$ & & & & $6.64 \pm 0.09 a$ \\
\hline & $\mathrm{SS} 2$ & $6.90 \pm 0.02 \mathrm{a}$ & $6.65 \pm 0.08 \mathrm{a}$ & $6.55 \pm 0.07 \mathrm{a}$ & $7.04 \pm 0.04 a$ & $0.05 \mathrm{a}$ & $0.02 \mathrm{a}$ \\
\hline & SS3 & $7.43 \pm 0.06 b^{*}$ & $7.34 \pm 0.07 b^{*}$ & $7.22 \pm 0.09 b$ & $7.90 \pm 0.01 b^{*}$ & $7.69 \pm 0.12 b^{*}$ & $7.34 \pm 0.07 b$ \\
\hline \multirow[t]{3}{*}{ Bac 303} & SS1 & & $9.13 \pm 0.07 b$ & & & & $8.77 \pm 0.03$ \\
\hline & $\mathrm{SS} 2$ & $9.38 \pm 0.05 b$ & $8.86 \pm 0.04 b$ & $8.64 \pm 0.08 b$ & $9.41 \pm 0.04 \mathrm{ab}$ & & $8.75 \pm 0.11$ \\
\hline & SS3 & $8.79 \pm 0.09 a^{*}$ & $8.14 \pm 0.08 \mathrm{a}^{*}$ & $7.96 \pm 0.13 a^{*}$ & $9.08 \pm 0.09 a^{*}$ & $8.39 \pm 0.02 *$ & $8.28 \pm 0.02 *$ \\
\hline \multirow[t]{3}{*}{ Ato 291} & SS1 & $8.85 \pm 0.10$ & $8.43 \pm 0.06$ & $8.20 \pm 0.17$ & $8.88 \pm 0.04$ & $8.50 \pm 0.18$ & $8.20 \pm 0.23$ \\
\hline & SS2 & $8.75 \pm 0.10$ & $8.38 \pm 0.08$ & $8.07 \pm 0.18$ & $8.73 \pm 0.10$ & $8.39 \pm 0.15$ & $8.18 \pm 0.17$ \\
\hline & SS3 & $9.01 \pm 0.13$ & $8.74 \pm 0.32$ & $8.48 \pm 0.28$ & $8.86 \pm 0.09$ & $8.50 \pm 0.17$ & $8.23 \pm 0.20$ \\
\hline \multirow{3}{*}{$\begin{array}{l}\text { EUB } 338 \\
\text { mixture }\end{array}$} & SS1 & $10.06 \pm 0.03 a$ & $10.01 \pm 0.08 \mathrm{a}$ & $9.82 \pm 0.08 \mathrm{a}$ & $10.03 \pm 0.06$ & $9.96 \pm 0.05$ & $9.64 \pm 0.08$ \\
\hline & $\mathrm{SS} 2$ & $10.00 \pm 0.08 a$ & $9.88 \pm 0.04 a$ & $9.69 \pm 0.08 \mathrm{a}$ & $10.04 \pm 0.05$ & $9.98 \pm 0.09$ & $9.60 \pm 0.13$ \\
\hline & SS3 & $10.26 \pm 0.02 b$ & $10.18 \pm 0.03 b$ & $10.08 \pm 0.05 b^{*}$ & $10.20 \pm 0.06$ & $10.13 \pm 0.04$ & $9.77 \pm 0.05^{*}$ \\
\hline
\end{tabular}

Values are based on the average of six gut models using faeces from three elderly subjects \pm SD.

Results are calculated based on the means of data from three consecutive days in each vessel and each steady state.

Lab 158 - lactobacilli/enterococci, Bif 164 - bifidobacteria, Erec 482 - Eubacterium rectale -

Clostridium coccoides, Chis 150 - the Clostridium histolyticum, Bcoa 191 - Bacillus spp., Bac 
303 - Bacteroides-Prevotella spp., Ato 291 - Atopobium, and EUB 338 mixture - total bacteria.

* Significance difference between $B$. coagulans and B-GOS treatment at SS3, p<0.05.

Significant differences $(\mathrm{p}<0.05)$ among SS1, SS2 and SS3. in the same vessel are indicated with different letters. 
Table 4 Short chain fatty acids concentration analysed by GC for three different vessels (Vessel 1, Vessel 2, Vessel 3) of in vitro colonic

models before adding any treatment at steady state (SS) 1, after adding high fat mixture at SS2, and after adding high fat mixture with B-

GOS/ B. coagulans treatment at SS3.

\begin{tabular}{|c|c|c|c|c|c|c|c|c|c|c|c|c|c|c|c|}
\hline & \multicolumn{3}{|c|}{ Acetic acid } & \multicolumn{3}{|c|}{ Propionic acid } & \multicolumn{3}{|c|}{ Butyric acid } & \multicolumn{3}{|c|}{ Iso-butyric acid } & \multicolumn{3}{|c|}{ Iso-valeric acid } \\
\hline & vessel 1 & vessel 2 & vessel 3 & vessel 1 & vessel 2 & vessel 3 & vessel 1 & vessel 2 & vessel 3 & vessel 1 & vessel 2 & vessel 3 & vessel 1 & vessel 2 & vessel 3 \\
\hline \multicolumn{16}{|c|}{ B-GOS } \\
\hline \multirow[t]{2}{*}{ SS1 } & $59.43 \pm$ & $70.42 \pm$ & $74.46 \pm$ & $31.38 \pm$ & $36.99 \pm$ & $39.39 \pm$ & $36.00 \pm$ & $40.76 \pm$ & $43.15 \pm$ & $0.88 \pm$ & $2.77 \pm$ & $3.37 \pm$ & $1.06 \pm$ & $3.04 \pm$ & $3.60 \pm$ \\
\hline & $5.57 \mathrm{a}$ & $3.95 \mathrm{a}$ & $5.50 \mathrm{a}$ & $2.66 \mathrm{~b}$ & $3.47 \mathrm{~b}$ & $3.32 \mathrm{~b}$ & $4.70 \mathrm{ab}$ & $4.16 \mathrm{a}$ & $5.31 \mathrm{a}$ & $0.34 b$ & $0.40 \mathrm{~b}$ & $0.21 b$ & $0.37 b$ & $0.16 b$ & $0.26 b$ \\
\hline \multirow[t]{2}{*}{$\mathrm{SS} 2$} & $51.46 \pm$ & $63.78 \pm$ & $68.46 \pm$ & $26.17 \pm$ & $32.38 \pm$ & $35.85 \pm$ & $25.19 \pm$ & $29.83 \pm$ & $31.99 \pm$ & $0.66 \pm$ & $2.58 \pm$ & $2.99 \pm$ & $0.86 \pm$ & $2.42 \pm$ & $3.20 \pm$ \\
\hline & $5.22 \mathrm{a}$ & $5.21 \mathrm{a}$ & $6.03 \mathrm{a}$ & $2.43 \mathrm{ab}$ & $2.40 \mathrm{ab}$ & $3.77 \mathrm{ab}$ & $6.22 \mathrm{a}$ & $4.91 \mathrm{a}$ & $4.71 \mathrm{a}$ & $0.15 \mathrm{ab}$ & $0.33 \mathrm{ab}$ & $0.05 \mathrm{ab}$ & $0.34 \mathrm{ab}$ & $0.22 b$ & $0.32 b$ \\
\hline \multirow[t]{2}{*}{ SS3 } & $86.51 \pm$ & $\begin{array}{l}102.35 \\
\pm\end{array}$ & $\begin{array}{l}106.70 \\
\pm\end{array}$ & $18.73 \pm$ & $23.92 \pm$ & $27.37 \pm$ & $48.30 \pm$ & $52.84 \pm$ & $57.96 \pm$ & $0.10 \pm$ & $1.45 \pm$ & $1.74 \pm$ & $0.08 \pm$ & $1.33 \pm$ & $1.93 \pm$ \\
\hline & $4.44 b^{*}$ & $6.75 b^{*}$ & $6.32 b^{*}$ & $3.16 \mathrm{a}$ & $2.96 \mathrm{a}$ & $2.58 \mathrm{a}$ & $2.31 \mathrm{~b}$ & $2.09 b^{*}$ & $3.39 b^{*}$ & $0.02 \mathrm{a}$ & $0.39 \mathrm{a}$ & $0.42 \mathrm{a}$ & $0.01 \mathrm{a}^{*}$ & $0.36 \mathrm{a}$ & $0.48 \mathrm{a}$ \\
\hline \multicolumn{16}{|c|}{ B. coagulans } \\
\hline \multirow[t]{2}{*}{ SS1 } & $56.76 \pm$ & $65.42 \pm$ & $70.62 \pm$ & $29.05 \pm$ & $34.71 \pm$ & $38.54 \pm$ & $35.78 \pm$ & $40.24 \pm$ & $41.75 \pm$ & $0.78 \pm$ & $3.08 \pm$ & $3.38 \pm$ & $1.25 \pm$ & $3.00 \pm$ & $3.49 \pm$ \\
\hline & $4.50 \mathrm{ab}$ & $4.72 \mathrm{ab}$ & $4.45 \mathrm{a}$ & 3.21 & 3.82 & 4.21 & $6.18 \mathrm{ab}$ & $3.78 \mathrm{ab}$ & $3.32 \mathrm{ab}$ & $0.22 b$ & $0.19 b$ & $0.30 \mathrm{~b}$ & $0.22 b$ & $0.17 b$ & $0.23 b$ \\
\hline \multirow[t]{2}{*}{ SS2 } & $48.24 \pm$ & $61.52 \pm$ & $65.12 \pm$ & $23.65 \pm$ & $28.74 \pm$ & $30.82 \pm$ & $24.57 \pm$ & $30.33 \pm$ & $32.73 \pm$ & $0.71 \pm$ & $2.78 \pm$ & $3.22 \pm$ & $1.12 \pm$ & $2.87 \pm$ & $3.33 \pm$ \\
\hline & $3.84 \mathrm{a}$ & $6.04 \mathrm{a}$ & $4.88 \mathrm{a}$ & 2.94 & 1.50 & 1.93 & $4.23 \mathrm{a}$ & $3.27 \mathrm{a}$ & $3.94 \mathrm{a}$ & $0.20 \mathrm{ab}$ & $0.37 b$ & $0.27 \mathrm{ab}$ & $0.24 b$ & $0.10 \mathrm{~b}$ & $0.26 b$ \\
\hline \multirow[t]{2}{*}{ SS3 } & $64.04 \pm$ & $79.08 \pm$ & $87.58 \pm$ & $27.71 \pm$ & $32.85 \pm$ & $37.69 \pm$ & $40.02 \pm$ & $42.70 \pm$ & $44.44 \pm$ & $0.19 \pm$ & $1.54 \pm$ & $2.45 \pm$ & $0.44 \pm$ & $1.95 \pm$ & $2.14 \pm$ \\
\hline & $4.31 b^{*}$ & $4.99 b^{*}$ & $5.72 b^{*}$ & 4.67 & 4.06 & 5.71 & $4.28 b$ & $2.65 b^{*}$ & $3.26 b^{*}$ & $0.12 \mathrm{a}$ & $0.38 \mathrm{a}$ & $0.30 \mathrm{a}$ & $0.17 \mathrm{a}^{*}$ & $0.17 \mathrm{a}$ & $0.21 \mathrm{a}$ \\
\hline
\end{tabular}

Values are based on the average of six gut models from three elderly subjects and reported as $\mathrm{mM} \pm \mathrm{SD}$. Results from each gut model are calculated 
based on the means of data from three consecutive days in each vessel and each steady state. * Significance difference between $B$. coagulans and

B-GOS treatment at SS3, p<0.05. Significant differences ( $p<0.05)$ among SS1, SS2 and SS3 in the same vessel are indicated with different letters. 
Figure 1 Effect of fermentation supernatants from three different vessels (Vessel 1, Vessel 2, Vessel 3) of in vitro colonic models before adding any treatment at steady state (SS) 1 , after adding high fat mixture at SS2, and after adding high fat mixture with B-GOS/ $B$. coagulans treatment at SS3 on microbiota composition. Values are mean \pm SD. * Significance difference between B. coagulans and B-GOS treatment at SS3, $<<0.05$. Significant differences $(\mathrm{p}<0.05)$ among SS1, SS2 and SS3 from same treatment are indicated with different letter.

Figure 2 Effect of fermentation supernatants from three different vessels (Vessel 1, Vessel 2, Vessel 3) of in vitro colonic models before adding any treatment at steady state (SS) 1 , after adding high fat mixture at SS2, and after adding high fat mixture with B-GOS/ B. coagulans treatment at SS3 on cytokine production by peripheral blood mononuclear cells (PBMC). Values are mean \pm SD. \#, significant differences from LPS value $\mathrm{p}<0.05 . *$, significance difference between $B$. coagulans and B-GOS treatment at SS3, $<<0.05$. Significant differences $(\mathrm{p}<0.05)$ among SS1 (no fat and treatment), SS2 (high fat mixture addition) and SS3 (high fat mixture with B. coagulans/B-GOS treatment) in the same vessel were indicated with different letters. Supernatants from PBMCs cultured without gut model supernatant were used as controls (+/-). In addition, cytokines in non-stimulated PBMC (blank) and in only pure gut model medium-treated PBMC (gut) were also determined. There were significant differences between them in cytokines IL-1 $\beta$, IL-6, IL-10 and TNF- $\alpha$ (not presented in figures). There was also no significant difference between LPS (LPS-stimulated PBMC) and gut+LPS (PBMC incubated with pure gut model medium and LPS).

Figure 3 Effect of fermentation supernatants from three different vessels (Vessel 1, Vessel 
2, Vessel 3) of in vitro colonic models before adding any treatment at steady state (SS) 1 , after adding high fat mixture at SS2, and after adding high fat mixture with B-GOS/ B. coagulans treatment at SS3 on SCFA. Values are mean \pm SD. * Significance difference between $B$. coagulans and B-GOS treatment at SS3, $\mathrm{p}<0.05$. Significant differences $(\mathrm{p}<0.05)$ among SS1, SS2 and SS3 from same treatment are indicated with different letter.

Supplementary Figure 2 Effect of fermentation supernatants from three different vessels (Vessel 1, Vessel 2, Vessel 3) of in vitro colonic models before adding any treatment at steady state (SS) 1, after adding high fat mixture at SS2, and after adding high fat mixture with B-GOS/ B. coagulans treatment at SS3 on microbiota composition. Values are mean \pm SD. * Significance difference between B. coagulans and B-GOS treatment at SS3, p<0.05. Significant differences $(\mathrm{p}<0.05)$ among SS1, SS2 and SS3 from same treatment are indicated with different letter.

Supplementary Figure 3 Effect of fermentation supernatants from three different vessels (Vessel 1, Vessel 2, Vessel 3) of in vitro colonic models before adding any treatment at steady state (SS) 1, after adding high fat mixture at SS2, and after adding high fat mixture with B-GOS/ B. coagulans treatment at SS3 on cytokine production by peripheral blood mononuclear cells (PBMC). Values are mean \pm SD. \#, significant differences from LPS value $\mathrm{p}<0.05 . *$, significance difference between $B$. coagulans and B-GOS treatment at $\mathrm{SS} 3, \mathrm{p}<0.05$. Significant differences $(\mathrm{p}<0.05)$ among SS1 (no fat and treatment), SS2 (high fat mixture addition) and SS3 (high fat mixture with B. coagulans/B-GOS treatment) in the same vessel were indicated with different letters. Supernatants from PBMCs cultured without gut model supernatant were used as controls (+/-). In addition, cytokines in non-stimulated PBMC (blank) 
and in only pure gut model medium-treated PBMC (gut) were also determined. There was also no significant difference between LPS (LPS-stimulated PBMC) and gut+LPS (PBMC incubated with pure gut model medium and LPS).

Supplementary Figure 4 Effect of fermentation supernatants from three different vessels (Vessel 1, Vessel 2, Vessel 3) of in vitro colonic models before adding any treatment at steady state (SS) 1, after adding high fat mixture at SS2, and after adding high fat mixture with B-GOS/ B. coagulans treatment at SS3 on SCFA. Values are mean \pm SD. * Significance difference between $B$. coagulans and B-GOS treatment at SS3, $<<0.05$. Significant differences $(p<0.05)$ among SS1, SS2 and SS3 from same treatment are indicated with different letter. 